\title{
June 27 Highlight and Commentary
}

\section{Helicobacter pylori infection reduces L-dopa absorption in PD}

Studying a large cohort of patients with Parkinson disease (PD) and motor fluctuations, Pierantozzi et al. observed a pharmacokinetic/clinically significant improvement during waking hours after eradication of gastric Helicobacter pylori. Improvement persisted at 3 months follow-up.

see page 1824

\section{Helicobacter pylori and levodopa absorption: A study in germ morefare}

Commentary by Robert L. Rodnitzky, MD

Levodopa is widely recognized as the most effective oral medication for relieving the signs and symptoms of PD. However, after a honeymoon period of months to years, during which time PD symptoms are remarkably and predictably relieved by levodopa, complications begin to appear. Among the most troubling of these adverse effects are motor fluctuations consisting of reemergence of symptoms appearing at progressively shorter intervals after scheduled dosages of medication (wearing off), wide swings in degree of benefit from successive dosages, and, perhaps most disturbing to patients, episodes of sudden and substantial loss of benefit seemingly unrelated to the timing and amount of levodopa dosing ("random offs"). The development of these motor fluctuations is related to the progressive loss of viable dopaminergic cells in the brain coupled with erratic delivery of levodopa across the blood-brain barrier. In the early stages of PD, there are a sufficient number of intact dopaminergic cells to take up exogenously administered levodopa, store it as dopamine, and release it under neural control during periods of time when levodopa delivery has temporarily failed, thereby preventing "off" episodes. With disease progression, more neurons die and this buffering capacity is lost with a temporary loss of clinical benefit resulting from any aberration in the con- tinuous availability of levodopa. Irregularity in levodopa delivery to the brain is common in PD and impaired gastrointestinal transit or absorption of the drug are among its major causes.

Orally administered levodopa must pass through the pylorus to the duodenum where it is absorbed. Because gastric motility is impaired in advanced PD, levodopa tablets can remain stagnant in the stomach, preventing or delaying any clinical effect. Once reaching the duodenum, absorption can be impaired by local structural or inflammatory pathology. A variety of strategies have been attempted to surmount these transit and absorption problems, including pharmacologic formulations to enhance levodopa passage through the pylorus, liquified suspensions of levodopa tablets, direct delivery of levodopa to the duodenum through an enteral tube, and the use of prokinetic drugs. None of these techniques has been entirely effective or entirely acceptable to patients.

Pierantozzi et al. have demonstrated that antibiotic eradication of gastrointestinal Helicobacter pylori is a relatively simple and inexpensive means of improving the absorption of levodopa. H pylori, a spiral shaped, Gram-negative bacterium, colonizes the stomach in approximately $50 \%$ of all people worldwide. Infection is typically contracted in childhood and persists for life. Most carriers are asymptomatic but in 10 to $15 \%$ the infection leads to peptic ulcer disease. The suggestion of this relationship by Marshall and Warren, ${ }^{1}$ initially ridiculed by the medical establishment, was ultimately confirmed and led to their receiving the 2005 Nobel Prize in medicine. Pierantozzi et al. have demonstrated that eradication of $H$ pylori in patients with PD resolves subclinical gastritis and duodenitis and significantly increases levodopa absorption leading to higher plasma levels of the drug. Most importantly, "on time" is impressively increased. The exact mechanism by which $H$ pylori eradication leads to this improvement in absorption is unknown, but the authors offer several reasonable physiologic and biochemical hypotheses. To be certain, further study of this phenomenon is in order. An equally important question raised by this article is whether we, as a specialty, are going to reflexively react with incredulity to the potential importance of $H$ pylori infection in our patients just as the gastroenterology community did 20 years ago, or are ready to begin ordering a simple screening test for this bacterium and change our "culture" in regard to PD therapy.

\section{Reference}

1. Marshall BJ, Warren JR. Unidentified curved bacilli in the stomach of patients with gastritis and peptic ulceration. Lancet 1984;1(8390):1311-1315.

see page 1824 


\section{Neurology}

June 27 Highlight and Commentary

Neurology 2006;66;1791

DOI 10.1212/01.wnl.0000227179.93348.1f

This information is current as of June 26, 2006

\section{Updated Information \&} Services

References

Permissions \& Licensing

Reprints including high resolution figures, can be found at: http://n.neurology.org/content/66/12/1791.full

This article cites 1 articles, 0 of which you can access for free at: http://n.neurology.org/content/66/12/1791.full\#ref-list-1

Information about reproducing this article in parts (figures,tables) or in its entirety can be found online at:

http://www.neurology.org/about/about_the_journal\#permissions

Information about ordering reprints can be found online:

http://n.neurology.org/subscribers/advertise

Neurology ${ }^{\circledR}$ is the official journal of the American Academy of Neurology. Published continuously since 1951, it is now a weekly with 48 issues per year. Copyright . All rights reserved. Print ISSN: 0028-3878. Online ISSN: 1526-632X.

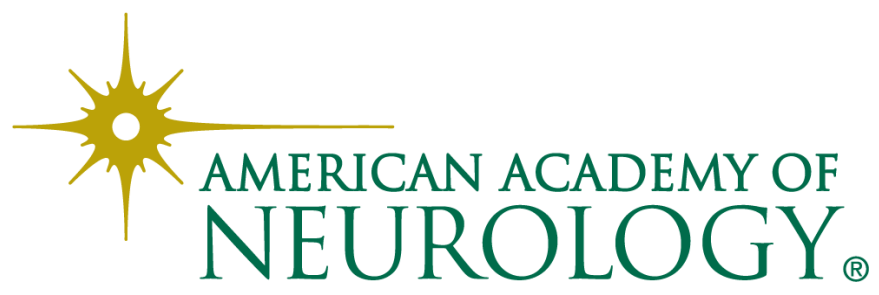

